\title{
CORRELATION BETWEEN PHYSICAL FITNESS AND MOTIVATION FOR PHYSICAL ACTIVITY IN CHILDREN WITH AUTISM SPECTRUM DISORDERS
}

\author{
Ali Hamade \\ Lviv State University of Physical Culture named after Ivan Bobersky, Ukraine \\ Oleksandra Petrusenko \\ Lviv State University of Physical Culture named after Ivan Bobersky. \\ Training and Rehabilitation Center of I-II levels "Dovira", Ukraine
}

\begin{abstract}
Information on the correlation of physical fitness indicators to indicators of motivation for physical activity (PA) in schoolchildren with autism spectrum disorders (ASD) is very limited. The lack of such information makes it impossible to collect informative tests that best assess the level of PA literacy. It also hampers the effective identification of appropriate and effective means for the formation of PA literacy among schoolchildren with ASD. The study aims at comparing the levels of physical fitness and motivation for PA in children with ASD with their peers without disorders; determining the degree of correlation between physical fitness and motivation for physical activity in children with ASD. Data were collected from two Ukrainian samples: 18 children with ASD aged 11-13 years, and 30 children aged 11-12 years without ASD diagnosis. Results. Most of the correlation coefficients between the indices of physical fitness and motivation for $P A$ in children with ASD (9/12) are reliable. This suggests that motivation to PA (defined by the CAPL-2 methodology) is an informative criterion of PA literacy of children with ASD. Significant correlations with motivation for PA in schoolchildren with ASD were observed in the results of two exercise tests.
\end{abstract}

Keywords: ASD, CAPL-2, children, correlation, motivation, physical activity literacy, physical fitness.

\section{Introduction}

The number of children with autism spectrum disorders (ASD) is growing worldwide. We observe a similar trend in Ukraine. As the incidence of ASD increases, so does the interest in ways to improve the health and quality of life of these people. It is known that children and adults with ASD experience sleep problems (Miano, Ferri, 2010), have more frequent health problems (including immune conditions, gastrointestinal disorders and sleep, seizures, obesity, dyslipidemia, hypertension and diabetes, stroke and Parkinson's disease, anxiety, 
hyperactivity, aggression and sensory impairment) (Zuckerman et al., 2014; Balogun, 2016), destructive behavior (stereotype, self-harm) (Smith \& Matson, 2010). A combination of several diagnoses occurs in $83 \%$ of cases (Levy et al., 2010). Children with ASD have lower levels of motor activity (Must et al., 2014; Tyler et al., 2014; Pan et al., 2016), significantly lower levels of physical development and physical fitness (Tyler et al., 2014; Pan et al., 2016; Pan et al., 2009) than their peers with normal development.

Exercise, in addition to improving physical fitness, reduces stress and anxiety, improves sleep, treats depression (Oriel et al., 2011; GarcíaVillamisar \& Dattilo, 2010). Therefore, they are considered an inexpensive safe and useful tool for disease prevention, development of psychomotor, cognitive and emotional spheres of children with ASD.

Research studies the relationship between physical activity (PA) and other indicators of how it can be affected. Research results (Pan et al., 2011) have shown that students with ASD are less physically active than their peers. However, when involving students without disabilities as teaching assistants in the process of inclusive physical education lessons in secondary school, students with ASD are modeled appropriate behavior that helps to increase the level of PA.

Other researchers (Barrodi et al., 2021) confirmed that the level of fine and gross motor skills depends on the degree of autism. Thus, the level of physical fitness can predict the degree of stereotypes, disorders of communication and social skills and even the degree of autism.

Knowledge of the relationship between physical fitness and indicators of students' with ASD motivation for PA would allow the purposeful use of appropriate physical exercises to adjust the indicators that motivate PA. Such information would allow to select test exercises that would best indicate the motivation of students with ASD to PA. Currently, there are some disparate facts about the interaction between physical fitness and children's with ASD It better tomotivation for PA, which does not allow to develop an effective program of training or an informative battery of test exercises of physical fitness to predict a number of other indicators.

The purpose of the study was to compare the level of physical fitness, as well as children's with autism spectrum disorders motivation for PA with their peers without disorders; to find out the degree of interaction between children's with autism spectrum disorders motivation for PA and the indicators of physical fitness. 
SOCIETY. INTEGRATION. EDUCATION

Proceedings of the International Scientific Conference. Volume III, May $28^{\text {th }}-29^{\text {th }}$, 2021. 28-36

\section{Methods and Organization}

Physical fitness was determined by the results of a series of test exercises described by the authors (Hamade \& Bodnar, 2020).

Evaluation Motivation and Confidence was conducted in accordance with the system of physical education literacy CAPL-2 Canadian Assessment of Physical Literacy - Second Edition (Longmuir et al., 2017). Participants were asked to answer the questionnaire questions about the degree of their participation in various forms of physical activity, attitude to PA and success in it. Parents or guardians of the child were involved in explaining the essence of the questions. According to the original method, the degree of motivation was determined in points. A maximum of 30 points could be scored. The number of points determined the level of motivation of each student (Table 1).

\section{Participants}

Data were collected from two Ukrainian samples: 18 children with autism spectrum disorders aged 11-13 years old (11.63 \pm 1.59 years old) (main groupMG), and 30 children aged 11-12 years old (11.47 \pm 0.51 years old) without ASD diagnosis (control group - CG). Samples were recruited in Indicators were collected in the Lviv Training and Rehabilitation Center "Dovira" and schools in Lviv (Ukraine). No differences in the performance of children were observed main and control group (Table 2).

Table 1 Interpretation of Points Obtained for Motivation

\begin{tabular}{|c|c|c|c|c|}
\hline \multirow{2}{*}{ Age } & \multicolumn{4}{|c|}{ The levels of motivation } \\
\cline { 2 - 5 } & beginning & progressing & achieving & excelling \\
\hline 10 years old & $<16.8$ & $16.8-23.5$ & $23.6-26.0$ & $>26.0$ \\
\hline 11 years old & $<16.8$ & $16.8-23.7$ & $23.6-26.0$ & $>26.0$ \\
\hline 12 years old & $<16.8$ & $16.8-23.7$ & $23.6-26.2$ & $>26.2$ \\
\hline
\end{tabular}

Table 2 Indicators of Study Participants

\begin{tabular}{|c|c|c|c|c|}
\hline \multirow{2}{*}{ Indexes } & \multicolumn{2}{|c|}{ Main group $(\mathrm{n}=18)$} & \multicolumn{2}{c|}{ Control group $(\mathrm{n}=30)$} \\
\cline { 2 - 5 } & $\mathrm{M} \pm \mathrm{SD}$ & $\min -\max$ & $\mathrm{M} \pm \mathrm{SD}$ & $\min -\max$ \\
\hline Age, years & $11.63 \pm 1.59$ & $11-13$ & $11.47 \pm 0.51$ & $11-12$ \\
\hline Body weight, $\mathrm{kg}$ & $44.53 \pm 10.58$ & $31-63$ & $42.97 \pm 7.86$ & $31-60$ \\
\hline Height, sm & $150.37 \pm 12.21$ & $132-171$ & $153.17 \pm 6.94$ & $140-165$ \\
\hline VMI, $\mathrm{kg} / \mathrm{m}^{2}$ & $18.41 \pm 4.99$ & $14.7-24.9$ & $18.22 \pm 2.45$ & $14.2-23.3$ \\
\hline
\end{tabular}

\section{Statistical analysis}

Data have been analysed descriptively using average (M), the corrected mean square deviation (SD), standard error (SE), the smallest value (Xmin), the highest value (Xmax), the median (Me). Data for children with ASD have been 
Hamade \& Petrusenko, 2021. Correlation Between Physical Fitness And Motivation For Physical Activity In Children With Autism Spectrum Disorders

compared with normative data and data for children without ASD. Associated 95\% confidence intervals were also calculated. Differences between groups have been determined using the Kruskal-Wallis ANOVA, the probability was set at $\mathrm{p}<0.05$. The close linkage has been established by the Brave-Pearson correlation coefficient.

\section{Research Results}

Physical fitness. The results of all test exercises (Table 3) MG children were significantly lower than CG. Statistically significant differences were observed in all tests. The biggest differences were between the results of children with ASD and participants without deviations in terms of strength endurance: according to the results of the test exercise "Keeping the bar on the forearms" children with ASD lagged 6 times. The results of the exercise "Jumping on 2 legs from circle to circle" of MG participants were 3 times lower, "Balancing on a bench on one leg" - 2 times lower, "Writing the letter" O "- 2.5 times lower compared to CG participants.

Table 3 Indicators of Physical Competence of Children with Autism Spectrum Disorders and Healthy Peers

\begin{tabular}{|c|c|c|c|c|c|}
\hline \multirow[b]{2}{*}{ Test } & \multicolumn{2}{|c|}{ Main group } & \multicolumn{2}{|c|}{ Control group } & \multirow{2}{*}{$\begin{array}{c}\text { The } \\
\text { difference } \\
\text { (in\%) } \\
\text { between MG } \\
\text { and CG }\end{array}$} \\
\hline & M & $\pm \mathrm{SD}$ & M & $\pm \mathrm{SD}$ & \\
\hline $\begin{array}{l}\text { Jumps on } 2 \text { legs from circle to circle, } \\
\text { sec }\end{array}$ & $11.89 *$ & 3.23 & 3.91 & 1.08 & 67.1 \\
\hline $\begin{array}{l}\text { Passing and catching the ball, the } \\
\text { number for } 30 \text { seconds }\end{array}$ & $11.62 *$ & 6.42 & 21.60 & 7.36 & 46.2 \\
\hline Pushing the medball from the chest, sec & $276.14 *$ & 101.17 & 720.17 & 244.53 & 61.7 \\
\hline Long jump from a place, sm & $94.18 *$ & 33.20 & 158.70 & 16.94 & 40.7 \\
\hline 4 balls, sec & $9.18 *$ & 2.70 & 5.09 & 2.04 & 44.6 \\
\hline Running $20 \mathrm{~m}$, sec & $5.71 *$ & 0.89 & 4.01 & 0.52 & 29.8 \\
\hline Walking along the line $4.5 \mathrm{~m}$, sec & $15.03 *$ & 6.27 & 6.95 & 1.19 & 53.8 \\
\hline $\begin{array}{l}\text { Maintenance flamingo poses on the } \\
\text { bench, sec }\end{array}$ & $30.49 *$ & 24.53 & 59.95 & 34.01 & 49.1 \\
\hline Holding the "bar" on the forearms, sec & $22.35 *$ & 32.82 & 136.6 & 103.28 & 83.6 \\
\hline $\begin{array}{l}\text { Clap your hands, amount for } 10 \\
\text { seconds }\end{array}$ & $27.79 *$ & 6.81 & 40.60 & 14.58 & 31.6 \\
\hline $\begin{array}{l}\text { Writing the letter "O", the number for } \\
10 \text { seconds }\end{array}$ & $9.43 *$ & 3.52 & 23.57 & 4.77 & 60.0 \\
\hline $\begin{array}{l}\text { Squats on two legs, the numbert for } 10 \\
\text { seconds }\end{array}$ & $7.91 *$ & 1.64 & 12.73 & 2.52 & 37.9 \\
\hline
\end{tabular}

* - differences are significant at $p<0.05$ 
SOCIETY. INTEGRATION. EDUCATION

Proceedings of the International Scientific Conference. Volume III, May $28^{\text {th }}-29^{\text {th }}$, 2021. 28-36

Motivation and Confidence. The children's from MG Motivation to PA was significantly $(\mathrm{p}<0.05)$ lower than in CG (Table 4): the schoolchildren's with ASD motivation in PA was estimated at $18.66 \pm 3.31$ points (out of 30 possible), which is significantly $(\mathrm{p}<0.05)$ less than in healthy children $(25.32 \pm 3.39$ points).

Table 4 Indicators of Motivation for Physical Activity of Children with Autism Spectrum Disorders and Healthy Peers

\begin{tabular}{|c|c|c|c|c|c|c|c|c|c|}
\hline \multirow{3}{*}{ Contingent } & \multirow{3}{*}{ Figures } & \multicolumn{6}{|c|}{$\begin{array}{c}\text { Domain Motivation and Confidencein } \\
\text { physical activity, (max } 30 \text { points) }\end{array}$} & \multirow{3}{*}{$\begin{array}{c}\text { Scores } \\
\text { (out of } \\
30 \\
\text { possible) }\end{array}$} & \multirow{3}{*}{ Level } \\
\hline & & \multicolumn{3}{|c|}{$\begin{array}{c}\text { Subdomain } \\
\text { Intrinsic Motivation } \\
\text { and Physical } \\
\text { Activity } \\
\text { Competence } \\
\text { (max } 15 \text { points) }\end{array}$} & \multicolumn{3}{|c|}{$\begin{array}{c}\text { Subdomain } \\
\text { Predilection and } \\
\text { Adequacy (max } 15 \\
\text { points) }\end{array}$} & & \\
\hline & & 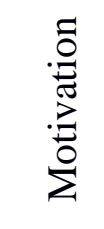 & 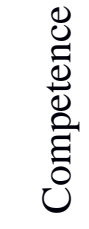 & 퓸 & 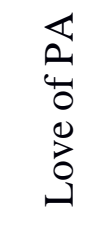 & 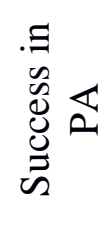 & 营 & & \\
\hline \multirow{2}{*}{$\begin{array}{c}\text { MG } \\
(\mathrm{n}=18)\end{array}$} & $\mathrm{M}$ & 5.97 & 3.75 & \multirow{2}{*}{9.72} & 4.61 & 4.34 & \multirow{2}{*}{8.95} & $18.66 *$ & \multirow{2}{*}{ progressing } \\
\hline & $\pm S D$ & 1.94 & 1.46 & & 1.09 & 1.31 & & 3.31 & \\
\hline \multirow{2}{*}{$\begin{array}{c}\mathrm{CG} \\
(\mathrm{n}=30)\end{array}$} & $\mathrm{M}$ & 7.05 & 5.50 & \multirow{2}{*}{12.55} & 6.62 & 6.14 & \multirow{2}{*}{12.76} & 25.32 & \multirow{2}{*}{ excelling } \\
\hline & $\pm \mathrm{SD}$ & 0.56 & 1.59 & & 1.04 & 0.96 & & 3.39 & \\
\hline
\end{tabular}

Symbols:

* - differences between the rates of children with ASD and healthy children are significant when $p<0.05$;

A - average, HA - higher than the average level of motivation for physical activity

At the same time, $82.4 \%$ of children from MG had high motivation to participate in PA, as in CG. However, the success in this activity in children from MG was significantly lower (3.75 \pm 1.46 points out of 7.5 possible) than in CG. As a result, the number of points of children from CO for the subdomain Intrinsic Motivation and Physical Activity Competence (9.72 points) was slightly lower than in CG (12.55 points). The sum of points for the second subdomain of children from MG (8.95 points) was also slightly lower than of children from CG (12.76 points).

Correlation analysis. As we can see (table 5), most of the correlation coefficients between indicators of physical fitness and motivation in children with ASD are reliable. Note that children's from MG indicators of 1 subdomain Intrinsic Motivation and Physical Activity Competence in PA have with the 
results of exercise a greater number of coefficients of medium and high degree (7 of 9 reliable) than the indicators of the 2nd subdomain Predilection and Adequacy (4 of 8) and domain Motivation and Confidence overall (6 out of 11). Thus, it is enough to know the results of one (first) subdomain of motivation to predict the level of physical fitness of children with ASD.

\section{Table 5 Correlation Analysis of the Results of Physical Fitness with Indicators of Motivation for Physical Activity}

\begin{tabular}{|c|c|c|c|c|}
\hline $\begin{array}{l}\text { Groups } \\
\text { indexe } \\
\text { s }\end{array}$ & Indexes & $\begin{array}{c}\text { Intrinsic } \\
\text { Motivation and } \\
\text { Physical } \\
\text { Activity } \\
\text { Competence } \\
\end{array}$ & $\begin{array}{c}\text { Predilection } \\
\text { and } \\
\text { Adequacy }\end{array}$ & $\begin{array}{l}\text { Motivation } \\
\text { and } \\
\text { Confidence }\end{array}$ \\
\hline \multirow[t]{3}{*}{1} & Walking on the line of $4.5 \mathrm{~m}$ & - & - & - \\
\hline & Squats on two legs for 10 seconds & 0.375 & - & 0.468 \\
\hline & Long jump from a place & - & - & 0.338 \\
\hline \multirow[t]{3}{*}{2} & Running $20 \mathrm{~m}$ & - & - & -0.516 \\
\hline & Writing the letter "O" $10 \mathrm{sec}$ & 0.494 & 0.602 & 0.378 \\
\hline & $\begin{array}{l}\text { Clapping in the palms for } 10 \\
\text { seconds }\end{array}$ & 0.589 & 0.434 & 0.289 \\
\hline \multirow[t]{3}{*}{3} & Holding the "bar" on the forearms & 0.774 & 0.361 & 0.605 \\
\hline & "4 balls" & -0.501 & -0.434 & -0.557 \\
\hline & $\begin{array}{l}\text { Holding the "flamingo" pose on the } \\
\text { bench }\end{array}$ & 0.658 & 0.198 & 0.526 \\
\hline \multirow[t]{3}{*}{4} & Pushing medball from the chest & 0.757 & 0.509 & 0.476 \\
\hline & $\begin{array}{l}\text { Passing and catching the ball for } 30 \\
\text { seconds }\end{array}$ & 0.615 & 0.515 & 0.725 \\
\hline & Jumping from circle to circle & 0.689 & 0.788 & 0.913 \\
\hline
\end{tabular}

Symbols:

1. The table presents only reliable coefficients (critical values: at the level of significance $p<0.05-0.361 ; p<0,01-0,463 ; p<0,001-0,570)$;

2. marked in bold significant relationships (moderate - 0.30-0.49, significant - 0.50-0.69, significant - 0.70-0.89, very significant - 0.90-0.99)

All test exercises, which are significantly correlated with motivation, were divided into 4 groups depending on the number and strength of correlation coefficients. Each of the subgroups received three test exercises.

\section{Discussion}

The motivation of children with ASD to participate in PA was high, as well as in healthy peers. PA brings joy to all children. They strive to become stronger, smarter and more enduring, aware of the benefits of exercise. However, the success in this activity in children with ASD was significantly 
lower. Therefore, the sum of points of children without ASD (12.55 points) had advantages in Intrinsic Motivation and Physical Activity Competence in comparison with children with ASD (9.72 points). It is difficult for children with ASD to learn new sports skills. They are often not athletically gifted and realize that they are inferior to other peers in agility, endurance and strength. Therefore, they like to dance, run, do gymnastics, play sports, spend active leisure time, take part in hiking trips, competitions or relay races, play football or hockey, etc. As a result, the sum of points for the subdomain Motivation and Confidence in children with ASD was slightly (8.95 points) lower than in healthy ones (12.76 points).

The results of physical fitness testing of children with ASD were significantly lower than of typically developed peers. The level of motivation for PA in children with ASD was also lower (progressing) than in healthy schoolchildren (excelling). This suggested the existence of a relationship between these groups of indicators.

The large number of reliable correlation coefficients between the indicators of physical fitness and motivation in children with ASD, established by us, indicates that the level of motivation can predict the level of physical fitness of these children. Or vice versa - the results of physical fitness standards contain information about intrinsic motivation (What motivates to PA?), Motor priorities (What types of PA do you like to do at leisure?) And attitudes to physical activity in general (What emotions are provoked by different means and forms of PA?). Also the data received by us testify that the motivation defined by a technique CAPL-2, serves as an informative criterion of PA competence of children with ASD. Our results on the number of coefficients of average and higher degree between the results of physical fitness and individual subdomains and domains of motivation indicate a relatively lower informativeness of the subdomain Predilection and Adequacy in determining the general level of physical literacy of children with ASD, or relatively higher informativeness of domain Intrinsic Motivation and Physical Activity Competence. Differences in the number of coefficients of the average and higher degree of the two domains can be explained by the wording of the questionnaire, as well as the ability of parents or guardians to convey their content to children with ASD. It is also possible that this specificity of the relationship between the motivation of physical fitness applies only to children with ASD. Additional research is needed to determine the real causes.

But what can be said unequivocally is that the test exercises of groups 4 and 5 can be recommended for inclusion in the battery of tests as informative for determining the motivation of children with ASD for PA, as they show relationships of medium density with two or more indicators of motivation . The following test exercises were included in the third and the fourth groups: 
Holding the "bar" on the forearms, "4 balls", Holding the "flamingo" pose on the bench; Passing and catching the ball for 30 seconds, jumping from circle to circle, as well as pushing the medball from the chest.

\section{Conclusions}

1. The results of test exercises of physical fitness, as well as level of children's with ASD motivation for PA were significantly lower than their typically developed peers. This suggested the existence of a relationship between these groups of indicators.

3. The level of motivation can predict the level of physical fitness of these children. The most informative are the results of such tests as Holding the "bar" on the forearms, "4 balls", Holding the "flamingo" pose on the bench; Passing and catching the ball for 30 seconds, Jumping from circle to circle, as well as Pushing the medball from the chest.

4. Motivation determined by the method CAPL-2, serves as an informative criterion of physical culture competence of children with ASD.

\section{References}

Balogun, F. (2016). Prevalence and Correlates of Obesity in Childhood Autism Spectrum Disorders: A Literature Review. J Psychiatry., 19, 385. DOI: https://doi.org/ 10.4172/2378-5756.1000385

Barrodi, S., Ghasemi, A., Kashi, A., \& Azimzadeh, E. (2021). The relationship between the motor skills level and the severity of autism disorder in children with autism. Pedagogy of Physical Culture and Sports, 25(1), 58-65. DOI: https://doi.org/10.15561/ 26649837.2021.0108

García-Villamisar, D., Dattilo, J. (2010). Effects of a leisure programme on quality of life and stress of individuals with ASD. J Intellect Disabil Res., 54(7), 611-9.

Hamade, A. \& Bodnar, I. (2020). Fizychna pratsezdatnist, fizychna pidhotovlenist ta fizychna aktyvnist shkoliariv z rozladamy autychnoho spektru. Sportyvnyi visnyk Prydniprovia, 1, 414-422.

Levy, S., Giarelli, E., Lee, L., Schieve L., Kirby, R., Cunniff, C., et al. (2010). Autism spectrum disorder and co-occurring developmental, psychiatric, and medical conditions among children in multiple populations of the United States. J Dev Behav Pediatr., 31(4), 267-75. DOI: https://doi.org/: 10.1097/DBP.0b013e3181d5d03b

Longmuir, P., Boyer, C., Lloyd M., Borghese, M., Knight, E., Saunders, T., et al. (2017). Canadian agility and movement skill assessment: validity, objectivity, and reliability evidence for children 8-12 years of age. J Sport Health Sci., 6(2), 231-40.

Miano, S., Ferri, R. (2010). Epidemiology and management of insomnia in children with autistic spectrum disorders. Pediatr Drugs., 12(2): 75-84. DOI: https://doi.org/10.2165/ 11316140-000000000-00000

Must, A., Phillips, S.M, Curtin, C., Anderson, S., Maslin, M., Lividini, K., et al. (2014). Comparison of sedentary behaviors between children with autism spectrum disorders 
and typically developing children. Autism, 18(4): 376-384. DOI: https://doi.org/ $10.1177 / 1362361313479039$

Oriel, K., George, C., Peckus, R., Semon, A. (2011). The effects of aerobic exercise on academic engagement in young children with autism spectrum disorder. Pediatr Phys Ther., 23(2), 187-93.

Pan, C., Tsai, C., Chu, C. (2009). Fundamental movement skills in children diagnosed with autism spectrum disorders and attention deficit hyperactivity disorder. J Autism Dev Disord., 39, 1964-1705.

Pan, C., Tsai, C., Chu, C., Sung, M., Ma, W., Huang, C. (2016). Objectively measured physical activity and health-related physical fitness in secondary school-aged male students with autism spectrum disorders. Phys Ther., 96(4), 511-520. DOI: https://doi.org/10.2522/ptj.20140353

Pan, C., Tsai, C., Hsieh, K. (2011). Physical activity correlates for children with autism spectrum disorders in middle school physical education. Research Quarterly for Exercise and Sport, 82(3), 491-8. DOI: https://doi.org/10.1080/02701367. 2011.10599782

Smith, K, Matson, J. (2010). Behavior problems: differences among intellectually disabled adults with co-morbid autism spectrum disorders and epilepsy. Res Dev Disabil., 31(5), 1062-1069. doi:10.1016/j.ridd.2010.04.003

Tyler, K., MacDonald, M., Menear, K. (2014). Physical activity and physical fitness of school-aged children and youth with autism spectrum disorders. Autism Res Treat., 312163, 1-6. DOI: https://doi.org/10.1155/2014/312163

Zuckerman, K., Hill, A., Guion, K., Voltolina, L., Fombonne, E. (2014). Overweight and obesity: prevalence and correlates in a large clinical sample of children with autism spectrum disorder. $J$ Autism Dev Disord., 44 (7), 1708-1719. DOI: https://doi.org/10.1007/s10803-014-2050-9 